
\title{
25 Research Square \\ Cardiac involvement in COVID-19 patients: mid-term follow up by cardiac magnetic resonance imaging
}

Hui Wang

Beijing Anzhen Hospital, Capital Medical University

Ruili Li

Beijing Youan Hospital, Capital Medical University

Hong Jiang

Beijing Anzhen Hospital, Capital Medical University

Zixu Yan

Beijing Anzhen Hospital, Capital Medical University

Xinyan Tao

Beijing Anzhen Hospital, Capital Medical University

Hongjun Li ( $\square$ lihongjun00113@126.com )

Beijing Youan Hospital, Capital Medical University

Lei Xu ( $\square$ leixu2001@hotmail.com )

Beijing Anzhen Hospital, Capital Medical University

\section{Research Article}

Keywords: COVID-19, cardiac involvement, cardiac dysfunction, cardiac magnetic resonance imaging

Posted Date: August 12th, 2020

DOI: https://doi.org/10.21203/rs.3.rs-57104/v1

License: (c) (i) This work is licensed under a Creative Commons Attribution 4.0 International License.

Read Full License 


\section{Abstract}

Background: Coronavirus disease 2019 (COVID-19) induces myocardial injury, either direct myocarditis or indirect injury due to systemic inflammatory response. Myocardial involvement has been proved to be one of the primary manifestations of COVID-19 infection, according to laboratory test, autopsy, and cardiac magnetic resonance imaging (CMRI). However, the middle-term outcome of cardiac involvement after the patients were discharged from the hospital is yet unknown. The present study aimed to evaluate mid-term cardiac sequelae in recovered COVID-19 patients by CMRI

Methods: A total of 47 recovered COVID-19 patients were prospectively recruited and underwent CMRI examination in this study. The CMRI protocol consisted of black blood fat-suppressed T2 weighted imaging (BB-T2WI), T2 star mapping, left ventricle cine imaging, pre- and post-contrast T1 mapping, and late gadolinium enhancement (LGE). Myocardium edema and LGE were assessed in recovered COVID-19 patients. The left ventricle (LV) and right ventricle (RV) function and LV mass were assessed and compared with normal controls.

Results: Finally, 44 recovered COVID-19 patients and 31 normal controls were included in this study. No edema was observed in any patient. LGE was found in 13 patients. All LGE lesions were located in the middle myocardium and/or sub-epicardium with a scattered distribution. Further analysis showed that LGE-positive patients had significantly decreased left ventricle peak global circumferential strain (LVpGCS), right ventricle peak global circumferential strain (RVpGCS), right ventricle peak global longitudinal strain (RVpGLS) as compared to non-LGE patients ( $p \bigotimes 0.05)$, while no difference was detected between the non-LGE patients and normal controls.

Conclusion: Myocardium injury existed in about $30 \%$ of COVID-19 patients. These patients had peak right ventricle strain that decreased at the 3-month follow-up. Cardiac MRI can monitor the COVID-19-induced myocarditis progression, and CMR strain analysis is a sensitive tool to evaluate the recovery of left ventricle circumferential contraction dysfunction and right ventricular dysfunction.

\section{Introduction}

Coronavirus disease 2019 (COVID-19) is a nascent pandemic. Until July 20, 2020, 14353494 confirmed cases, including 603703 deaths, were reported to the World Health Organization ${ }^{1}$. Data from previous studies suggested that acute cardiac injury occurred in 20\% COVID-19 patients ${ }^{2}$. In hospitalized patients, the cardiac injury was up to $30 \%$ and caused $40 \%$ deaths $s^{3-6}$. The mechanisms of cardiac injury are direct myocarditis (direct myocardial infection by SARS-CoV-2) or indirect factors, such as cardiac stress due to respiratory failure, indirect injury from systemic inflammatory response-cytokine release syndrome, stress cardiomyopathy, or a combination of all these factors ${ }^{6-9}$.

Cardiovascular magnetic resonance imaging (CMRI) can visualize and quantify heart volume and function and characterize the myocardial tissue; thus, it has been used as a gold standard non-invasive 
imaging tool in cardiovascular medicine ${ }^{10}$. A recent single-center study from Wuhan demonstrated that more than half of the recovered COVID-19 patients sustain cardiac edema, fibrosis, and impaired right ventricle (RV) contractile function ${ }^{11}$. However, in this small-sample retrospective study, only patients with reported cardiac symptoms were included. The middle-term outcome of cardiac involvement in COVID-19 patients is yet unknown. Thus, the present study aimed to evaluate mid-term cardiac sequelae in recovered COVID-19 patients by CMRI.

\section{Methods}

\section{Study design and participants}

For this prospective, single-center study, we recruited consecutive COVID-19 patients from May 8 to July 20, 2020. The inclusion criteria were as follows: (1) Patients were previously confirmed to have SARSCoV-2 infection, (2) patients were recovered from COVID-19 and discharged from the hospital for ${ }^{12}$ weeks, (3) patients agreed to participate in the study and signed informed consent. The exclusion criteria were as follows: (1) Patients has undergone pacemaker surgery, (2) patients with uncontrolled high blood pressure, (3) patients with coronary heart disease (evidence of coronary artery stenosis $>50 \%$ ) or previous myocardial infarction, (4) patients with moderate to severe valvular dysfunction, (5) patients with previous atrial fibrillation, (6) previous heart failure, (7) previous myocarditis, (8) patients with known cardiomyopathy, (9) patients with severe renal insufficiency (creatinine clearance rate $<30 \mathrm{~mL} / \mathrm{min} / 1.73$ $\mathrm{m}^{2}$, (9) patients who cannot cooperate with breath-holding and cannot undergo CMR examination, (10) pregnant women, (11) patients are not suitable as clinical subjects due to other factors.

Age- and sex-matched healthy controls, who underwent the cardiac MRI exams in our hospital previously, were selected from a health screening database. All the controls showed normal ECG, echocardiography, and cardiac MRI and did not present any cardiovascular disease or systemic inflammation. The present study was approved by the local institutional review board hospital (KS2020001), and informed consent was obtained from all patients.

\section{MRI scanning protocol}

All patients underwent MRI examinations on a 3T MR scanner (Ingenia CX, Philips Healthcare, Best, The Netherlands). The cardiac MRI protocol consisted of black blood fat-suppressed T2 weighted imaging (BB-T2WI), T2 star mapping, left ventricle cine imaging including four chambers, two-chamber, short axis, pre- and post-contrast T1 mapping, and late gadolinium enhancement (LGE).

BB-T2WI was performed in short axis using multishot turbo spin echo (TSE) sequence with time of repetition $(T R)=2$ heart beat periods, time of echo $(T E)=75 \mathrm{~ms}$, voxel size $=1.7 \times 1.7 \times 8 \mathrm{~mm}^{3}$, field of view $(\mathrm{FOV})=380 \times 380 \mathrm{~mm}^{2}$, flip angle $(\mathrm{FA})=90^{\circ}$, and acceleration factor $=2$. T2 star mapping was carried out by a turbo field echo (TFE) sequence with 15 TEs from $1.15 \mathrm{~ms}$ to $16 \mathrm{~ms}$, TR $=29 \mathrm{~ms}$, voxel size $=1.8 \times 1.8 \times 15 \mathrm{~mm}^{3}, \mathrm{FOV}=300 \times 300 \mathrm{~mm}^{2}, \mathrm{FA}=25^{\circ}$, and acceleration factor $=3$. The cine 
scanning was conducted by a balanced steady state-free precession (bSSFP) sequence, with TR/TE = $3.0 / 1.52 \mathrm{~ms}, \mathrm{FA}=45^{\circ}$, voxel size $=1.8 \times 1.8 \times 8 \mathrm{~mm}^{3}, \mathrm{FOV}=270 \times 270 \mathrm{~mm}^{2}$, and acceleration factor $=$ 1.5 or 3.6 depending on the number of slices acquired per breath hold. For short axis cine imaging, 9 slices were acquired to cover the entire left ventricle. Modified Look-locker inversion recovery (MOLLI) acquisition scheme was applied for both pre- and post-contrast T1 mapping using single-shot bSSFP sequence with TR/TE $=3.3 / 1.5 \mathrm{~ms}$, voxel size $=2 \times 2 \times 15 \mathrm{~mm}^{3}, \mathrm{FOV}=300 \times 300 \mathrm{~mm}^{2}, \mathrm{FA}=20^{\circ}$, and acceleration factor $=2$. LGE imaging was implemented $10 \mathrm{~min}$ after intravenous administration of contrast medium $(0.2 \mathrm{mmol} / \mathrm{kg}$; Magnevist gadopentetate dimeglumine, Bayer Healthcare, Bayer, Bergkamen, Germany) using a phase-sensitive inversion-recovery (PSIR) TFE sequence with TR/TE = $6.1 / 3.0$, voxel size $=1.6 \times 1.9 \times 8 \mathrm{~mm}^{3}, \mathrm{FOV}=350 \times 350 \mathrm{~mm}^{2}, \mathrm{FA}=25^{\circ} / 5^{\circ}$, and acceleration factor $=2$. All the protocols were executed using ECG trigger and breath holding.

\section{MRI images analysis}

Anonymized images were evaluated by two radiologists (HW and LX with 8 and 12 years of cardiac MRI diagnosis experience, respectively). Myocardium edema was defined as the regional or global signal hyperintensity on $\mathrm{T}_{2} \mathrm{WI}^{13}$. Myocardial edema ratio (ER) was defined as the ratio $>1.9$ between myocardial signal intensity (SI) and skeletal muscle SI. High signal area of inadequately suppressed slow-flowing cavitary blood was excluded carefully ${ }^{14}$. The LGE lesion was quantified using full width at half-maximum method ${ }^{15}$. The visual presence and different patterns (epicardial, mid-wall, or transmural) on the LGE images were assessed by two radiologists independently. Any discrepancies were resolved by reaching consensus through consultation. The ratio between the LGE volume and the total LV myocardium volume (LGE/myocardium) in the LGE-positive patients was calculated.

The left ventricle (LV) and RV function and LV mass were assessed based on the short-axis cine images using cvi42 software (Circle Cardiovascular Imaging Inc., Calgary, Canada). Endocardial and epicardial borders, with papillary muscles excluded from volumes, were identified automatically by the software and amended by a radiologist $(\mathrm{WH})$. LV and RV range were defined from the planes of the mitral valve and tricuspid valve to the apex, respectively, on 4-chamber cine images in both diastolic and systolic phases. Short-axis images were divided into size-based equiangular segments with RV-LV junction as the reference point. LV and RV function parameters, end-diastolic volume (EDV), end-systolic volume (ESV), stroke volume (SV), cardiac output (CO), ejection fraction (EF), and LV mass were calculated automatically. All volumes and masses were normalized to the body surface area (BSA).

Three-dimensional (3D) global radial strain (GRS), global circumferential strain (GCS), and global longitudinal strain (GLS) of LV and RV were obtained using cvi42. The end-diastolic phase served as the reference. Contours of endo- and epicardial myocardium of short-axis, as well as the 2-, 3-, 4-chamber long-axis cine images, were drawn by a radiologist $(\mathrm{WH})$. Patients were further divided into two subgroups based on visual LGE.

\section{Statistical analysis}


All data were analyzed using SPSS software version 25.0 (SPSS Inc., Chicago, IL, USA). Normally distributed continuous variables were expressed as mean \pm standard deviation. Two-tailed one-way ANOVA was used to analyze the differences between LGE, non-LGE, and normal control groups. Categorical variables were expressed as counts and percentages. T-test was used to compare the means with normal distribution, and the Mann-Whitney $U$ test was used to compare the variables with nonnormal distribution between LGE and non-LGE groups. $\chi^{2}$ test was used to explore the statistical significance of CMR parameters among LGE, non-LGE, and normal control groups. A two-sided $p<0.05$ was considered as statistically significant.

\section{Results}

\section{Population characteristics}

From May 8 to July 20, 2020, 47 patients who recovered from COVID-19 were recruited in this study and were subjected to CMR examination. According to the CMR diagnosis, one patient was excluded because of moderate tricuspid regurgitation, one was excluded because of hypertrophic cardiomyopathy, and one was excluded because of hypertensive cardiomyopathy. Finally, 44 recovered patients and 31 normal controls were included in this study.

The clinical characteristics of COVID-19 patients are reported in Table 1. The average age of COVID-19 patients was $47.55 \pm 13.32$ years, and the cohort comprised of 19 (43.19\%) men. The average duration from discharge from the hospital to CMR examination was $102.52 \pm 20.56$ days. A quarter of the patients performed regular exercise, only one patient smoked, and three drank small amount alcohol every day (less than 25mg per day). New York Heart Function Classification from I to IV was 21, 13, 8, 2, respectively. According to the Diagnosis and Treatment Protocol of Novel Coronavirus issued by the National Health Commission of the People's Republic of China ${ }^{12}$, the moderate, severe, and critically ill types COVID-19 pneumonia were 32 of 44 (72.73\%), 11 (25\%), and 1 (2.3\%), respectively; 11 (25\%) patients had hypertension, 8 (18.180\%) patients had diabetes, and $16(36.36 \%)$ patients had hyperlipidemia before COVID-19. Non-patients had chronic obstructive pulmonary disease, cerebrovascular disease, or chronic renal diseases. Moreover, 2 (4.55\%) patients had hepatitis B before COVID-19. Twenty-four (54.5\%) patients were administered antiviral (Kaletra, Arbidol, oseltamivir, and interferon) , 12 (27.28\%) patients were given antibiotic (moxifloxacin, cefixime, and cefuroxime) and 13 patients were given corticosteroid therapy, while 10 (22.73\%) patients were given high-flow oxygen support, 2 (4.55\%) patients were administered intravenous immunoglobulin, and 2 (4.55\%) were given angiotensin-converting enzyme inhibitors (ACEI) or angiotensin receptor blockers (ARB) (Table 1).

\section{Laboratory results}

During hospitalization, troponin I (TNI), (creatine kinase) CK, Creatine phosphokinase-Mb (CKMB), myohemoglobin (MYO), C-reactive protein (CRP), serum potassium, and serum calcium were measured in all patients at least one time. The median (interquartile range, IQR) or average \pm standard deviation (SD) 
results of the highest value were as follows: TNl: $0.02(0.01-0.02) \mathrm{ng} / \mathrm{mL}, \mathrm{CK}: 69(13.7-141.25) \mathrm{U} / \mathrm{L}$, CKMB: 0.33 (0.18 -0.64) ng/mL, MYO: $56.8 \pm 42.72 \mathrm{ng} / \mathrm{mL}$, CRP: $43.03 \pm 42.85 \mathrm{mg} / \mathrm{L}$, serum potassium: $3.80 \pm 0.34 \mathrm{mmol} / \mathrm{L}$, serum calcium: $1.27 \pm 0.24 \mathrm{mmol} / \mathrm{L}$. TNI in LGE group and non-LGE group were $0.021(0.01-0.043)$ and $0.013(0.01-0.02)$, respectively, with significant difference between the two groups (pष0.05). (Table 1).

\section{CMR results}

\section{Myocardium edema and LGE}

No edema (high signal intensity on T2WI) or myocardium hemorrhage was observed in any patient; however, LGE was detected in 13 patients. All LGE lesions were located in the middle myocardium and/or sub-epicardium with a scattered distribution (Fig. 1). Among a total of 208 myocardial segments in 13 patients, most LGE lesions were located at the inferior and inferior-lateral segments at the base and midchamber. The Bull's eye illustration (Fig. 2) shows us the number of myocardial LGE distributed in AHA 16 segments' model in all 13 patients. The inferior wall and inferior-lateral wall of the basal segment was the most frequently involved segment (10/12 patients). The median of LGE/myocardium ratio was $1.7 \%$ $(1.1 \%-3.0 \%)$.

\section{LV/RV morphological, function, and strain analysis}

Table 2 shows the values for global LV and RV morphological and functional parameters and the measurement of the 3D global CMR feature-tracking deformation parameters. Strikingly, no significant difference was detected in the LV and RV morphological parameters (EDV, ESV, and mass) among COVID19 patients with and without LGE and normal controls. Although no significant difference was detected in the LV and RV traditional function parameters - EF, cardiac output (CO) , cardiac index (CI), stroke volume (SV); LV peak 3D-GCS were decreased in COVID-19 patients with visual LGE (-15.08 \pm 10.33$)$ on CMR images as compared to healthy controls $(-19.39 \pm 3.02)(p<0.05)$. Both peak 3D GCS and GLS of RV in COVID-19 patients with LGE $(-9.42 \pm 3.44$ and $-7.75 \pm 3.98$, respectively) were significantly decreased as compared to COVID-19 patients without LGE (-12.08 \pm 3.98 and $-12.89 \pm 3.01$, respectively) and normal control (-12.85 \pm 4.33 and $-11.30 \pm 3.87$, respectively) (both $p \otimes 0.05$ ). However, no difference (peak 3D GCS and GLS of RV) was detected between COVID-19 patients without LGE and the normal controls $(p>0.05)$.

\section{Discussion}

The present study found that about 30\% (13 out of 44) of the COVID-19 patients had myocardium injury (manifested as LGE on CMR delay enhanced images) at the 3-month follow up, while no edema was observed. Further analysis showed that LGE-positive patients had a decrease in the LV GCS as compared to normal control and a significant decrease in the RV GCS, and GLS as compared to non-LGE patients.

Myocardial involvement has been proved to be one of the primary manifestations of COVID-19 infection

by laboratory, autopsy, and $\mathrm{CMR}^{16-18}$ as compared to other members of the coronavirus family ${ }^{19}$. A recent 
study demonstrated that in the recovered COVID-19 patients with cardiac symptoms, $54 \%$ had myocardium edema, and $31 \%$ had $\mathrm{LGE}^{11}$. In the current study, no edema was observed, which might indicate that all myocardial injury has passed the acute stage at the 3-month follow-up ${ }^{13,20}$. The persistence of visual LGE at 3-month follow-up reflecting necrosis (persistent inflammation) or scar (fibrosis) might be caused by COVID-19 and needs to be elucidated further ${ }^{21}$. Yet, visual LGE indicated that up to $30 \%$ COVID-19 patients have irreversible myocardial injury ${ }^{22,23}$, which is consistent with the findings of the previous study and can confirm one of the main mechanisms of COVID-19 induced direct myocardial injury-myocarditis ${ }^{24-26}$. In addition, the presence of LGE has been proven to be an independent predictor of all-cause mortality and cardiac mortality in myocarditis ${ }^{27,28}$. Since the LGE/myocardium ratio was small, the cardiac status of COVID-19 patients with LGE needs to be closely monitored.

All the LGE lesions were located in the middle myocardium and/or sub-epicardium, wherein the fibers are oriented transversely, and the torque enhances shortening in the circumferential direction ${ }^{29,30}$. This may be the reason for LV 3D GCS to be oriented along the perimeter in short axis view ${ }^{29}$ and decreased in the COVID-19 patients with LGE. This finding prompts us to focus on the left ventricle circumferential contraction dysfunction in these patients in addition to impaired RV function.

Furthermore, impaired RV function has been demonstrated by either echocardiography or $\mathrm{CMR}^{11,31,32}$. $\mathrm{RV}$ strain has been recommended to assess the RV function in clinical scenarios with suspected RV dysfunction ${ }^{33}$. Although our results showed that the RV traditional morphological and function parameters are in a normal range, the RV strain in COVID-19 patients with LGE was significantly decreased as compared to those without LGE and normal controls. This phenomenon indicated that COVID-19 patients with LGE still had RV dysfunction, which could be detected by CMR strain analysis. COVID-19 results in acute respiratory distress syndrome (ARDS) ${ }^{34}$ and is frequently associated with RV dysfunction, increased pulmonary resistance ${ }^{35}$, increased values of systolic pulmonary arterial pressure, increased RV afterload ${ }^{36,37}$, severe hypoxia, oxidative stress, and increased myocardial oxygen demand induced by ARDS $^{38}$.

According to a recent systematic echocardiographic study, the most frequent abnormality induced by COVID-19 was RV dilation with or without dysfunction ${ }^{35}$. However, our results only showed RV dysfunction in patients with LGE. No RV morphological (EDV and ESV) difference was detected at the 3month follow up, which might be attributed to improved pneumonia; subsequently, the RV rapidly returns to normal size while the RV strain is still decreased.

\section{Limitations}

Nevertheless, the current study has some limitations. First, the lack of baseline CMR examination limits the evaluation of the progress of heart involvement. Second, the sample size was small. Third, the majority of the included patients had moderate and severe COVID-19, and hence, our study could not 
reflect the full spectrum of critical COVID-19 patients. Fourth, we had data of only a 3-month MRI examination, and thus, a long-time follow-up is essential to determine the progression or regression of cardiac involvement.

\section{Conclusions}

Myocardium injury existed in about $30 \%$ of the COVID-19 patients, who also had left ventricle circumferential strain and right ventricle strain that decreased at the 3-month follow-up. Cardiac MRI can monitor the COVID-19-induced myocarditis progress. CMR strain analysis is a sensitive tool to evaluate the recovery of left ventricle circumferential contraction dysfunction and right ventricular dysfunction.

\section{List Of Abbreviations}

COVID-19: coronavirus disease 2019

CMRI: cardiac magnetic resonance imaging

BB-T2WI: black blood fat-suppressed T2 weighted imaging

TSE: turbo spin echo

TR: time of repetition

TE: time of echo

FOV: field of view

FA囚flip angle

TEE: turbo field echo

bSSFP: balanced steady state-free precession

MOLLI: modified Look-locker inversion recovery

PSIR: phase-sensitive inversion-recovery

LGE: late gadolinium enhancement

ER: edema ratio

SI: signal intensity

LV: left ventricle

$\mathrm{RV}$ : right ventricle 
EDV: end-diastolic volume

ESV: end-systolic volume

SV: stroke volume

CO: cardiac output

EF: ejection fraction

BSA: body surface area

3D: three-dimensional

GRS: global radial strain

GCS: global circumferential strain

GLS: global longitudinal strain

ACEl: angiotensin-converting enzyme inhibitor

ARB: angiotensin receptor blocker

TNI: troponin I

CK: creatine kinase

CKMB: creatine phosphokinase-Mb

MYO: myohemoglobin

CRP: C-reactive protein

IQR: interquartile range

SD: standard deviation

LVpGCS: left ventricle peak global circumferential strain

RVpGCS: right ventricle peak global longitudinal strain

ARDR: acute respiratory distress syndrome

\section{Declarations}

Ethics approval and consent to participate 
The study was approved by the local committees, and all patients gave informed consent for their medical data to be used in this study.

\section{Consent for publication}

The manuscript is approved by all authors for publication

\section{Availability of data and material}

The datasets used and/or analyzed during the current study are available from the corresponding author on reasonable request.

\section{Competing interests}

The authors declare that they have no competing interests

\section{Funding}

This study was supported by a grants from National Natural Science Foundation of China (U1908211) $\rrbracket$ the National Key Research and Development Program of China (2016YFC1300300) \and Capital Medical Development Research Foundation of China (PXM2020_026272_000013) for Dr. L. Xu.

And grants from Beijing Municipal Health Commission, technology achievements and appropriate technology promotion project (2020-TG-002) and You'an Medical Development Project of COVID-19 Emergency Prevention and Control Public (BJYAYY-2020YC-03) for Dr. H. Li.

\section{Disclosures}

All authors have reported that they have no relationships relevant to the contents of this paper to disclose.

\section{Authors' contributions}

All authors made substantial contributions to conception, design and statistical analysis of the study. All authors were actively involved in reviewing and drafting the manuscript. All authors have approved the final version of this manuscript.

\section{References}

1. WHO coronavirus disease (COVID-19) dashboard. Geneva: World Health Organization, 2020. Available online: https://covid19.who.int/. In. 2020/7/4 edn.

2. Bavishi C, Bonow RO, Trivedi V, Abbott JD, Messerli FH, Bhatt DL. Acute myocardial injury in patients hospitalized with COVID-19 infection: A review. Prog Cardiovasc Dis 2020, doi:10.1016/j.pcad.2020.05.013. 
3. Shi S, Qin M, Shen B, Cai Y, Liu T, Yang F, et al. Association of Cardiac Injury With Mortality in Hospitalized Patients With COVID-19 in Wuhan, China. JAMA Cardiol 2020, doi:10.1001/jamacardio.2020.0950.

4. Ruan Q, Yang K, Wang W, Jiang L, Song J. Correction to: Clinical predictors of mortality due to COVID-19 based on an analysis of data of 150 patients from Wuhan, China. Intensive Care Med 2020; 46: 1294-1297, doi:10.1007/s00134-020-06028-z.

5. Guo T, Fan Y, Chen M, Wu X, Zhang L, He T, et al. Cardiovascular Implications of Fatal Outcomes of Patients With Coronavirus Disease 2019 (COVID-19). JAMA Cardiol 2020, doi:10.1001/jamacardio.2020.1017.

6. Akhmerov A, Marban E. COVID-19 and the Heart. Circ Res 2020; 126: 1443-1455, doi:10.1161/CIRCRESAHA.120.317055.

7. Madjid M, Safavi-Naeini P, Solomon SD, Vardeny O. Potential Effects of Coronaviruses on the Cardiovascular System: A Review. JAMA Cardiol 2020, doi:10.1001/jamacardio.2020.1286.

8. Clerkin KJ, Fried JA, Raikhelkar J, Sayer G, Griffin JM, Masoumi A, et al. COVID-19 and Cardiovascular Disease. Circulation 2020; 141: 1648-1655, doi:10.1161/CIRCULATIONAHA.120.046941.

9. Cheng R, Leedy D. COVID-19 and acute myocardial injury: the heart of the matter or an innocent bystander? Heart 2020, doi:10.1136/heartjnl-2020-317025.

10. Schulz-Menger J, Bluemke DA, Bremerich J, Flamm SD, Fogel MA, Friedrich MG, et al. Standardized image interpretation and post-processing in cardiovascular magnetic resonance - 2020 update : Society for Cardiovascular Magnetic Resonance (SCMR): Board of Trustees Task Force on Standardized Post-Processing. J Cardiovasc Magn Reson 2020; 22: 19, doi:10.1186/s12968-02000610-6.

11. Huang L ZP, Tang D, Zhu T, Han R, Zhan C, Liu W, Zeng H, Tao Q, Xia L. Cardiac involvement in recovered COVID-19 patients identified by magnetic resonance imaging. JACC: Cardiovascular Imaging 2020, doi:https://doi.org/10.1016/j.jcmg.2020.05.004.

12. China NHCotPsRo. Diagnosis and Treatment Protocol of Novel Coronavirus (trial version 6th). National Health Commission of the People's Republic of China Website Available at:http://wwwnhcgovcn/xcs/zhengcwj/202003/4856d5b0458141fa9f376853224d41d7shtml 2020.

13. Ferreira VM, Schulz-Menger J, Holmvang G, Kramer CM, Carbone I, Sechtem U, et al. Cardiovascular Magnetic Resonance in Nonischemic Myocardial Inflammation: Expert Recommendations. J Am Coll Cardiol 2018; 72: 3158-3176, doi:10.1016/j.jacc.2018.09.072.

14. Friedrich MG, Sechtem U, Schulz-Menger J, Holmvang G, Alakija P, Cooper LT, et al. Cardiovascular magnetic resonance in myocarditis: A JACC White Paper. J Am Coll Cardiol 2009; 53: 1475-1487, doi:10.1016/j.jacc.2009.02.007.

15. Grani C, Eichhorn C, Biere L, Kaneko K, Murthy VL, Agarwal V, et al. Comparison of myocardial fibrosis quantification methods by cardiovascular magnetic resonance imaging for risk stratification of 
patients with suspected myocarditis. J Cardiovasc Magn Reson 2019; 21: 14, doi:10.1186/s12968019-0520-0.

16. Buja LM, Wolf DA, Zhao B, Akkanti B, McDonald M, Lelenwa L, et al. The emerging spectrum of cardiopulmonary pathology of the coronavirus disease 2019 (COVID-19): Report of 3 autopsies from Houston, Texas, and review of autopsy findings from other United States cities. Cardiovasc Pathol 2020; 48: 107233, doi:10.1016/j.carpath.2020.107233.

17. Gravinay P, Issa N, Girard D, Camou F, Cochet H. CMR and serology to diagnose COVID-19 infection with primary cardiac involvement. Eur Heart J Cardiovasc Imaging 2020, doi:10.1093/ehjci/jeaa169.

18. Han H, Xie L, Liu R, Yang J, Liu F, Wu K, et al. Analysis of heart injury laboratory parameters in 273 COVID-19 patients in one hospital in Wuhan, China. J Med Virol 2020; 92: 819-823, doi:10.1002/jmv.25809.

19. Ansari Ramandi MM, Baay M, Naderi N. Does the novel coronavirus 2019 like heart more than the other family members of coronaviruses? J Cardiovasc Thorac Res 2020; 12: 156-157, doi:10.34172/jcvtr.2020.27.

20. Vermes $E$, Childs $H$, Faris $P$, Friedrich MG. Predictive value of CMR criteria for LV functional improvement in patients with acute myocarditis. Eur Heart J Cardiovasc Imaging 2014; 15: 11401144, doi:10.1093/ehjci/jeu099.

21. Berg J, Kottwitz J, Baltensperger N, Kissel CK, Lovrinovic M, Mehra T, et al. Cardiac Magnetic Resonance Imaging in Myocarditis Reveals Persistent Disease Activity Despite Normalization of Cardiac Enzymes and Inflammatory Parameters at 3-Month Follow-Up. Circ Heart Fail 2017; 10, doi:10.1161/CIRCHEARTFAILURE.117.004262.

22. Luetkens JA, Homsi R, Dabir D, Kuetting DL, Marx C, Doerner J, et al. Comprehensive Cardiac Magnetic Resonance for Short-Term Follow-Up in Acute Myocarditis. J Am Heart Assoc 2016; 5 , doi:10.1161/JAHA.116.003603.

23. Zagrosek A, Abdel-Aty H, Boye P, Wassmuth R, Messroghli D, Utz W, et al. Cardiac magnetic resonance monitors reversible and irreversible myocardial injury in myocarditis. JACC Cardiovasc Imaging 2009; 2: 131-138, doi:10.1016/j.jcmg.2008.09.014.

24. Rali AS, Ranka S, Shah Z, Sauer AJ. Mechanisms of Myocardial Injury in Coronavirus Disease 2019. Card Fail Rev 2020; 6: e15, doi:10.15420/cfr.2020.10.

25. Dhakal BP, Sweitzer NK, Indik JH, Acharya D, William P. SARS-CoV-2 Infection and Cardiovascular Disease: COVID-19 Heart. Heart Lung Circ 2020, doi:10.1016/j.hlc.2020.05.101.

26. Babapoor-Farrokhran S, Gill D, Walker J, Rasekhi RT, Bozorgnia B, Amanullah A. Myocardial injury and COVID-19: Possible mechanisms. Life Sci 2020; 253: 117723, doi:10.1016/j.Ifs.2020.117723.

27. Grun S, Schumm J, Greulich S, Wagner A, Schneider S, Bruder O, et al. Long-term follow-up of biopsyproven viral myocarditis: predictors of mortality and incomplete recovery. J Am Coll Cardiol 2012; 59: 1604-1615, doi:10.1016/j.jacc.2012.01.007.

28. Barone-Rochette G, Augier C, Rodiere M, Quesada JL, Foote A, Bouvaist H, et al. Potentially simple score of late gadolinium enhancement cardiac MR in acute myocarditis outcome. J Magn Reson 
Imaging 2014; 40: 1347-1354, doi:10.1002/jmri.24504.

29. Jeung MY, Germain P, Croisille P, El ghannudi S, Roy C, Gangi A. Myocardial tagging with MR imaging: overview of normal and pathologic findings. Radiographics 2012; 32: 1381-1398, doi:10.1148/rg.325115098.

30. Sengupta PP, Tajik AJ, Chandrasekaran K, Khandheria BK. Twist mechanics of the left ventricle: principles and application. JACC Cardiovasc Imaging 2008; 1: 366-376, doi:10.1016/j.jcmg.2008.02.006.

31. Mahmoud-Elsayed HM, Moody WE, Bradlow WM, Khan-Kheil AM, Senior J, Hudsmith LE, et al. Echocardiographic Findings in Patients With COVID-19 Pneumonia. Can J Cardiol 2020, doi:10.1016/j.cjca.2020.05.030.

32. Sud K, Vogel B, Bohra C, Garg V, Talebi S, Lerakis S, et al. Echocardiographic Findings in Patients with COVID-19 with Significant Myocardial Injury. J Am Soc Echocardiogr 2020, doi:10.1016/j.echo.2020.05.030.

33. Claus P, Omar AMS, Pedrizzetti G, Sengupta PP, Nagel E. Tissue Tracking Technology for Assessing Cardiac Mechanics: Principles, Normal Values, and Clinical Applications. JACC Cardiovasc Imaging 2015; 8: 1444-1460, doi:10.1016/j.jcmg.2015.11.001.

34. Chen N, Zhou M, Dong X, Qu J, Gong F, Han Y, et al. Epidemiological and clinical characteristics of 99 cases of 2019 novel coronavirus pneumonia in Wuhan, China: a descriptive study. Lancet 2020; 395: 507-513, doi:10.1016/S0140-6736(20)30211-7.

35. Szekely Y, Lichter Y, Taieb P, Banai A, Hochstadt A, Merdler I, et al. The Spectrum of Cardiac Manifestations in Coronavirus Disease 2019 (COVID-19) - a Systematic Echocardiographic Study. Circulation 2020, doi:10.1161/CIRCULATIONAHA.120.047971.

36. Bouferrache $\mathrm{K}$, Vieillard-Baron A. Acute respiratory distress syndrome, mechanical ventilation, and right ventricular function. Curr Opin Crit Care 2011; 17: 30-35, doi:10.1097/MCC.0b013e328342722b.

37. Bonizzoli M, Cipani S, Lazzeri C, Chiostri M, Ballo P, Sarti A, et al. Speckle tracking echocardiography and right ventricle dysfunction in acute respiratory distress syndrome a pilot study.

Echocardiography 2018; 35: 1982-1987, doi:10.1111/echo.14153.

38. Tahir F, Bin Arif T, Ahmed J, Malik F, Khalid M. Cardiac Manifestations of Coronavirus Disease 2019 (COVID-19): A Comprehensive Review. Cureus 2020; 12: e8021, doi:10.7759/cureus.8021.

\section{Tables}

Table 1: Clinical characteristics, laboratory measurements, complications during hospitalization and treatment before discharge of recovered COVID-19 patients. 


\begin{tabular}{|c|c|c|c|c|}
\hline Characteristic & $\begin{array}{l}\text { Total COVID-19 } \\
\text { patients } \\
(\mathrm{n}=44)\end{array}$ & $\begin{array}{l}\text { LGE } \\
(\mathrm{N}=13)\end{array}$ & $\begin{array}{l}\text { Non-LGE } \\
(\mathrm{N}=31)\end{array}$ & $\begin{array}{l}\mathrm{P}- \\
\text { Value }\end{array}$ \\
\hline \multirow[t]{2}{*}{ Age (yrs) } & \multirow[t]{2}{*}{$47.55 \pm 13.32$} & 53.15 & 45.19 & \multirow[t]{2}{*}{0.07} \\
\hline & & 14.53 & 12.27 & \\
\hline Gender & 19 (43.19\%) & $4(30.77 \%)$ & $15(48.39 \%)$ & 0.34 \\
\hline $\mathrm{BSA}\left(\mathrm{kg} / \mathrm{m}^{2}\right)$ & $1.76 \pm 0.19$ & $1.73 \pm 0.17$ & $1.77 \pm 0.2$ & 0.63 \\
\hline HR (bpm) & $66.15 \pm 11.65$ & $64.08 \pm 6.82$ & $67.0 \pm 13.21$ & 0.32 \\
\hline Duration between discharged from hospital to CMR & $102.52 \pm 20.56$ & 100.77 & 103.26 & 0.72 \\
\hline examination (day) & & \pm 20.25 & \pm 20.98 & \\
\hline Regular exercise & $10(22.73 \%)$ & $3(23.08 \%)$ & $7(22.58 \%)$ & 1.0 \\
\hline Smoke & $1(2.27 \%)$ & 0 & $1(3.23 \%)$ & NA \\
\hline Alcohol & $3(6.82 \%)$ & $1(7.69 \%)$ & $2(6.45 \%)$ & 1.0 \\
\hline NYHA I/II/III/IV & $21 / 13 / 8 / 2$ & $4 / 5 / 3 / 1$ & $17 / 8 / 5 / 1$ & 0.52 \\
\hline $\begin{array}{l}\text { Clinical COVID-19 pneumonia types, } \\
\text { moderate/severe/critical }\end{array}$ & $32 / 11 / 1$ & $7 / 5 / 1$ & $25 / 6 / 0$ & 0.10 \\
\hline \multicolumn{5}{|l|}{ Comorbidities } \\
\hline Hypertension & $11(25 \%)$ & 5 (38.46\%) & $6(19.35 \%)$ & 0.18 \\
\hline Diabetes mellites & $8(18.18 \%)$ & $2(15.38 \%)$ & $6(19.35 \%)$ & 1.0 \\
\hline Hyperlipidemia & $16(36.36 \%)$ & $3(23.08 \%)$ & $13(41.94 \%)$ & 0.31 \\
\hline Chronic obstructive pulmonary disease & 0 & 0 & 0 & NA \\
\hline Cerebrovascular disease & 0 & 0 & 0 & NA \\
\hline Chronic renal diseases & 0 & 0 & 0 & NA \\
\hline Hepatitis B & $2(4.55 \%)$ & $1(7.69 \%)$ & $1(3.23 \%)$ & 0.51 \\
\hline Laboratory findings & & & & \\
\hline $\mathrm{CK}(\mathrm{u} / \mathrm{l}) *$ & $69(13.7-141.25)$ & $57(44.5-167)$ & $76 \quad(45 \quad-$ & 0.85 \\
\hline & & & 142) & \\
\hline $\mathrm{CKMB}(\mathrm{ng} / \mathrm{ml}) *$ & $0.33(0.18-0.64)$ & $0.32(0.11-$ & $0.33(0.19-$ & 0.86 \\
\hline & & $0.73)$ & $0.64)$ & \\
\hline MYO (ng/ml) & $56.8 \pm 42.72$ & 66.92 & 52.55 & 0.31 \\
\hline & & 59.74 & \pm 33.55 & \\
\hline
\end{tabular}




\begin{tabular}{|c|c|c|c|c|}
\hline \multirow[t]{2}{*}{$\mathrm{TNI}(\mathrm{ng} / \mathrm{ml}) *$} & \multirow[t]{2}{*}{$0.02(0.01-0.02)$} & $0.021 \quad(0.01$ & $0.013 \quad(0.01$ & 0.04 \\
\hline & & $-0.043)$ & $-0.02)$ & \\
\hline \multirow[t]{2}{*}{ CRT (mg/l) } & \multirow[t]{2}{*}{$43.03 \pm 42.85$} & 54.82 & 38.08 & \multirow[t]{2}{*}{0.24} \\
\hline & & \pm 54.12 & \pm 37.07 & \\
\hline Serum Potassium (mmol/l) & $3.80 \pm 0.34$ & $3.71 \pm 0.32$ & $3.84 \pm 0.34$ & 0.24 \\
\hline Serum calcium (mmol/l) & $1.27 \pm 0.24$ & $1.33 \pm 0.32$ & $1.25 \pm 0.21$ & 0.33 \\
\hline \multicolumn{5}{|l|}{ Other complications during hospitalization } \\
\hline cardiac arrythmia & 0 & 0 & 0 & NA \\
\hline Renal injury & $4(9.09 \%)$ & $1(7.69 \%)$ & $3(9.68 \%)$ & 1.0 \\
\hline Liver injury & $19(43.18 \%)$ & $5(38.46 \%)$ & $14(45.16 \%)$ & 0.68 \\
\hline \multicolumn{5}{|l|}{ Treatment before discharge } \\
\hline Antiviral therapy & $24(54.5 \%)$ & $9(69.23 \%)$ & 15 (48.35\%) & 0.21 \\
\hline Antibiotic therapy & $12(27.28 \%)$ & $5(38.46 \%)$ & $7(22.58 \%)$ & 0.28 \\
\hline Use of corticosteroid & $13(29.55 \%)$ & $6(46.15 \% \%)$ & 7 (22.58\%) & 0.12 \\
\hline Non-invasive ventilation of high-flow nasal cannula & $10(22.73 \%)$ & $5(38.46 \%)$ & $5(16.13 \%)$ & 0.11 \\
\hline \multicolumn{5}{|l|}{ oxygen } \\
\hline Intravenous immunoglobulin & $2(4.55 \%)$ & $1(7.69 \%)$ & $1(3.23 \%)$ & 0.51 \\
\hline Use of ACEI/ARB & $2(4.55 \%)$ & $1(7.69 \%)$ & $1(3.23 \%)$ & 0.51 \\
\hline
\end{tabular}

* Median (IQR)

LGE: late gadolinium enhancement

Table 2 Cardiac MRI parameters of recovered COVID-19 patients and normal controls. 


\begin{tabular}{|c|c|c|c|c|c|c|c|c|}
\hline Characteristic & $\begin{array}{l}\text { Total } \\
(n=75)\end{array}$ & $\begin{array}{l}\text { LGE } \\
(n=13)\end{array}$ & $\begin{array}{l}\text { Non-LGE } \\
(n=31)\end{array}$ & $\begin{array}{l}\text { NC } \\
(n=31)\end{array}$ & $\begin{array}{l}\text { P-Value } \\
\text { (LGE vs Non- } \\
\text { LGE vs NC) }\end{array}$ & $\begin{array}{l}\text { P-Value } \\
\text { (LGE vs } \\
\text { Non- } \\
\text { LGE) }\end{array}$ & $\begin{array}{l}\text { P- } \\
\text { Value } \\
\text { (LGE } \\
\text { vs } \\
\text { NC) }\end{array}$ & $\begin{array}{l}\text { p-Value } \\
\text { (Non- } \\
\text { LGE } \\
\text { NC) }\end{array}$ \\
\hline (yrs) & $47.35 \pm$ & $53.15 \pm$ & 45.19 & 47.06 & 0.15 & 0.05 & 0.14 & 0.55 \\
\hline Average \pm SD & 12.31 & 14.53 & \pm 12.27 & \pm 11.02 & & & & \\
\hline Gender, Male & $\begin{array}{l}38 \\
(50.67 \%)\end{array}$ & $\begin{array}{l}4 \\
(30.77 \%)\end{array}$ & $\begin{array}{l}15 \\
(48.39 \%)\end{array}$ & 19 (61.29\%) & 0.17 & 0.34 & 0.06 & 0.31 \\
\hline BSA $\left(\mathrm{kg} / \mathrm{m}^{2}\right)$ & $\begin{array}{l}1.78 \\
\pm 0.18\end{array}$ & $\begin{array}{l}1.73 \\
\pm 0.16\end{array}$ & $\begin{array}{l}1.77 \\
\pm 0.19\end{array}$ & $1.81 \pm 0.18$ & 0.38 & 0.59 & 0.20 & 0.33 \\
\hline HR (bpm) & $\begin{array}{l}66.35 \\
\pm 10.60\end{array}$ & $\begin{array}{l}63.77 \pm \\
6.63\end{array}$ & $\begin{array}{l}67.23 \\
\pm 13.38\end{array}$ & $66.57 \pm 8.77$ & 0.61 & 0.33 & 0.43 & 0.81 \\
\hline LVEDV & $\begin{array}{l}129.11 \\
\pm 25.54\end{array}$ & $\begin{array}{l}120.87 \\
\pm 26.80\end{array}$ & $\begin{array}{l}130.88 \\
\pm 27.79\end{array}$ & $\begin{array}{l}130.78 \\
\pm 22.68\end{array}$ & 0.45 & 0.24 & 0.25 & 0.99 \\
\hline LVESV & $\begin{array}{l}48.52 \\
\pm 12.59\end{array}$ & $\begin{array}{l}42.84 \\
\pm 9.67\end{array}$ & $\begin{array}{l}49.75 \\
\pm 13.32\end{array}$ & $\begin{array}{l}49.67 \\
\pm 12.60\end{array}$ & 0.20 & 0.10 & 0.10 & 0.98 \\
\hline LVSV & $\begin{array}{l}80.56 \\
\pm 17.07\end{array}$ & $\begin{array}{l}78.00 \\
\pm 21.03\end{array}$ & $\begin{array}{l}81.14 \\
\pm 16.61\end{array}$ & $\begin{array}{l}81.05 \\
\pm 17.07\end{array}$ & 0.84 & 0.58 & 0.60 & 0.98 \\
\hline LVEF & $\begin{array}{l}62.48 \\
\pm 5.67\end{array}$ & $\begin{array}{l}64.25 \\
\pm 5.90\end{array}$ & $\begin{array}{l}62.22 \\
\pm 4.37\end{array}$ & $62.00 \pm 6.69$ & 0.46 & 0.28 & 0.23 & 0.88 \\
\hline LVCO & $\begin{array}{l}5.28 \\
\pm 1.15\end{array}$ & $\begin{array}{l}4.91 \\
\pm 1.10\end{array}$ & $\begin{array}{l}5.34 \\
\pm 1.09\end{array}$ & $5.37 \pm 1.22$ & 0.44 & 0.25 & 0.23 & 0.93 \\
\hline LVCI & $\begin{array}{l}2.96 \\
\pm 0.58\end{array}$ & $\begin{array}{l}2.82 \\
\pm 0.46\end{array}$ & $\begin{array}{l}3.03 \\
\pm 0.62\end{array}$ & $2.95 \pm 0.59$ & 0.54 & 0.27 & 0.50 & 0.59 \\
\hline LVmass & $\begin{array}{l}76.65 \\
\pm 15.14\end{array}$ & $\begin{array}{l}72.53 \\
\pm 14.54\end{array}$ & $\begin{array}{l}74.32 \\
\pm 15.37\end{array}$ & $\begin{array}{l}80.71 \\
\pm 14.65\end{array}$ & 0.14 & 0.72 & 0.10 & 0.97 \\
\hline LVEDV/BSA & $\begin{array}{l}72.41 \\
\pm 11.70\end{array}$ & $\begin{array}{l}69.30 \pm \\
10.60\end{array}$ & $\begin{array}{l}73.78 \\
\pm 12.72\end{array}$ & $\begin{array}{l}72.35 \\
\pm 11.17\end{array}$ & 0.52 & 0.25 & 0.43 & 0.63 \\
\hline LVESV/BSA & $\begin{array}{l}27.14 \\
\pm 6.40\end{array}$ & $\begin{array}{l}24.69 \pm \\
5.12\end{array}$ & $\begin{array}{l}27.81 \\
\pm 6.40\end{array}$ & $27.51 \pm 6.80$ & 0.31 & 0.14 & 0.19 & 0.85 \\
\hline LVSV/BSA & $\begin{array}{l}45.25 \\
\pm 7.89\end{array}$ & $\begin{array}{l}44.58 \\
\pm 8.56\end{array}$ & $\begin{array}{l}45.96 \\
\pm 7.80\end{array}$ & 44.817 .91 & 0.81 & 0.60 & 0.93 & 0.57 \\
\hline LVCO/BSA & 2.97 & 2.82 & 3.04 & $2.96 \pm 0.58$ & 0.49 & 0.24 & 0.44 & 0.59 \\
\hline
\end{tabular}




\begin{tabular}{|c|c|c|c|c|c|c|c|c|}
\hline & \pm 0.57 & \pm 0.46 & \pm 0.60 & & & & & \\
\hline \multirow[t]{2}{*}{ LVCI/BSA } & 1.68 & 1.63 & 1.75 & $1.64 \pm 0.35$ & 0.50 & 0.37 & 0.93 & 0.29 \\
\hline & \pm 0.39 & \pm 0.25 & \pm 0.48 & & & & & \\
\hline \multirow[t]{2}{*}{ LVmass/BSA } & 42.85 & 41.62 & 41.82 & $44.41 \pm 5.68$ & 0.13 & 0.91 & 0.13 & 0.07 \\
\hline & \pm 5.62 & \pm 5.56 & \pm 5.38 & & & & & \\
\hline \multirow[t]{2}{*}{ RVEDV } & 128.81 & 118.06 & 129.63 & 133.50 & 0.34 & 0.31 & 0.14 & 0.54 \\
\hline & \pm 31.52 & \pm 32.81 & \pm 34.18 & \pm 27.91 & & & & \\
\hline \multirow[t]{2}{*}{ RVESV } & 54.35 & 47.27 & 56.65 & 55.03 & 0.30 & 0.13 & 0.20 & 0.73 \\
\hline & \pm 18.34 & \pm 15.02 & \pm 21.31 & \pm 16.05 & & & & \\
\hline \multirow[t]{2}{*}{ RVSV } & 74.49 & 70.78 & 72.06 & 78.47 & 0.30 & 0.84 & 0.22 & 0.18 \\
\hline & \pm 18.70 & \pm 22.62 & \pm 19.23 & \pm 16.12 & & & & \\
\hline \multirow[t]{2}{*}{ RVEF } & 58.14 & 59.46 & 56.60 & $59.12 \pm 6.52$ & 0.35 & 0.26 & 0.89 & 0.20 \\
\hline & \pm 7.67 & \pm 8.62 & \pm 8.29 & & & & & \\
\hline \multirow[t]{2}{*}{ RVCO } & 4.87 & 4.45 & 4.75 & $5.17 \pm 1.00$ & 0.16 & 0.46 & 0.08 & 0.18 \\
\hline & \pm 1.22 & \pm 1.32 & \pm 1.33 & & & & & \\
\hline \multirow[t]{2}{*}{ RVCI } & 2.75 & 2.56 & 2.73 & $2.84 \pm 0.49$ & 0.40 & 0.40 & 0.18 & 0.51 \\
\hline & \pm 0.61 & \pm 0.68 & \pm 0.69 & & & & & \\
\hline \multirow[t]{2}{*}{ RVEDV/BSA } & 71.32 & 67.56 & 72.40 & 71.81 & 0.569 & 0.30 & 0.36 & 0.87 \\
\hline & \pm 13.82 & \pm 14.42 & \pm 15.20 & \pm 12.23 & & & & \\
\hline \multirow[t]{2}{*}{ RVESV/BSA } & 30.38 & 27.02 & 31.78 & $30.49 \pm 8.39$ & 0.30 & 0.12 & 0.25 & 0.61 \\
\hline & \pm 9.08 & \pm 6.97 & \pm 10.33 & & & & & \\
\hline \multirow[t]{2}{*}{ RVSV/BSA } & 41.48 & 40.54 & 40.77 & $42.58 \pm 7.92$ & 0.68 & 0.94 & 0.50 & 0.44 \\
\hline & \pm 9.04 & \pm 10.89 & \pm 9.45 & & & & & \\
\hline \multirow[t]{2}{*}{ RVCO/BSA } & 2.74 & 2.56 & 2.70 & $2.85 \pm 0.46$ & 0.32 & 0.50 & 0.15 & 0.33 \\
\hline & \pm 0.61 & \pm 0.68 & \pm 0.70 & & & & & \\
\hline \multirow[t]{2}{*}{ RVCI/BSA } & 1.56 & 1.49 & 1.57 & $1.58 \pm 0.30$ & 0.75 & 0.51 & 0.47 & 0.94 \\
\hline & \pm 0.39 & \pm 0.41 & \pm 0.46 & & & & & \\
\hline \multirow{2}{*}{\multicolumn{9}{|c|}{$\begin{array}{l}\text { 3D-Strain } \\
\text { analysis }\end{array}$}} \\
\hline & & & & & & & & \\
\hline LVPRS & 42.61 & 40.48 & 46.31 & 39.78 & 0.39 & 0.37 & 0.91 & 0.19 \\
\hline
\end{tabular}

3D-Strain

analysis

$\begin{array}{lllllllll}\text { LVPRS } & 42.61 & 40.48 & 46.31 & 39.78 & 0.39 & 0.37 & 0.91 & 0.19 \\ & \pm 19.54 & \pm 18.71 & \pm 23.00 & \pm 15.77 & & & & \\ \text { LVPCS } & -17.53 & -15.08 & -16.69 & -19.39 & 0.08 & 0.45 & 0.04 & 0.10 \\ & \pm 6.45 & \pm 10.33 & \pm 6.93 & \pm 3.02 & & & & \\ \text { LVPLS } & -12.71 & -11.91 & -12.71 & -13.06 & 0.58 & 0.47 & 0.30 & 0.68\end{array}$




\begin{tabular}{|c|c|c|c|c|c|c|c|c|}
\hline & \pm 3.32 & \pm 3.90 & \pm 3.60 & \pm 2.79 & & & & \\
\hline \multirow[t]{2}{*}{ RVPRS } & 31.55 & 31.37 & 28.75 & 34.43 & 0.16 & 0.49 & 0.42 & 0.06 \\
\hline & \pm 12.59 & \pm 14.53 & \pm 11.11 & \pm 10.35 & & & & \\
\hline \multirow[t]{2}{*}{ RVPCS } & -11.94 & -9.42 & -12.08 & $-12.85 \pm 4.33$ & 0.04 & 0.05 & 0.01 & 0.46 \\
\hline & \pm 4.17 & \pm 3.44 & \pm 3.98 & & & & & \\
\hline \multirow[t]{2}{*}{ RVPLS } & -11.34 & -7.75 & -12.89 & $-11.30 \pm 3.87$ & 0.00 & 0.003 & 0.00 & 0.08 \\
\hline & \pm 3.95 & \pm 3.98 & \pm 3.01 & & & & & \\
\hline
\end{tabular}

LGE: late gadolinium enhancement

NC: normal control

\section{Figures}

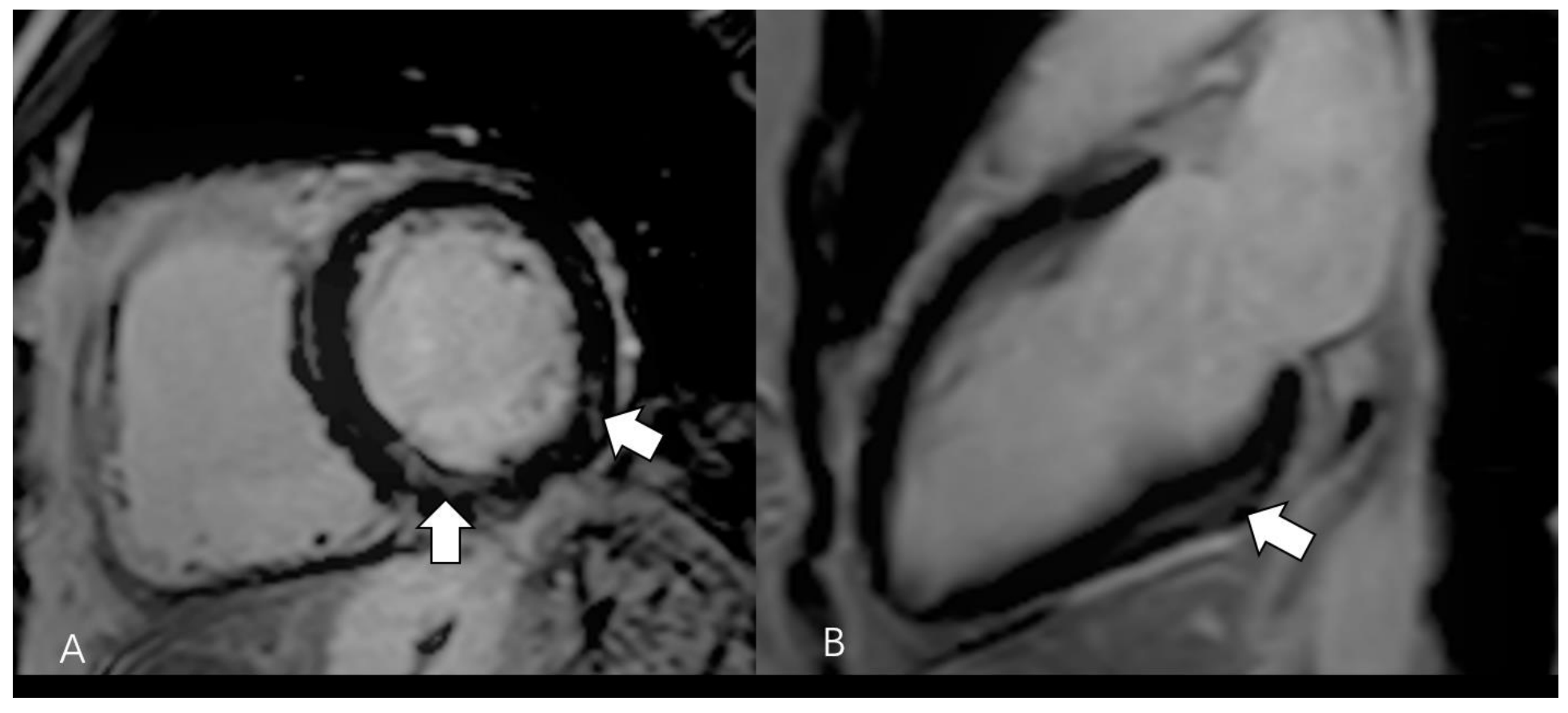

\section{Figure 1}

Illustration of myocardial injury location in recovered COVID-19 patients A: A 36-year-old male patient's short axis PSIR image shows LGE located at the sub-epicardium and mid-myocardium of inferior and inferior-septal wall (white arrow). B: A 63-year-old female patient's long axis PSIR image shows LGE located at inferior mid-myocardium (white arrow). PSIR: phase-sensitive inversion recovery LGE: Iate gadolinium enhancement 


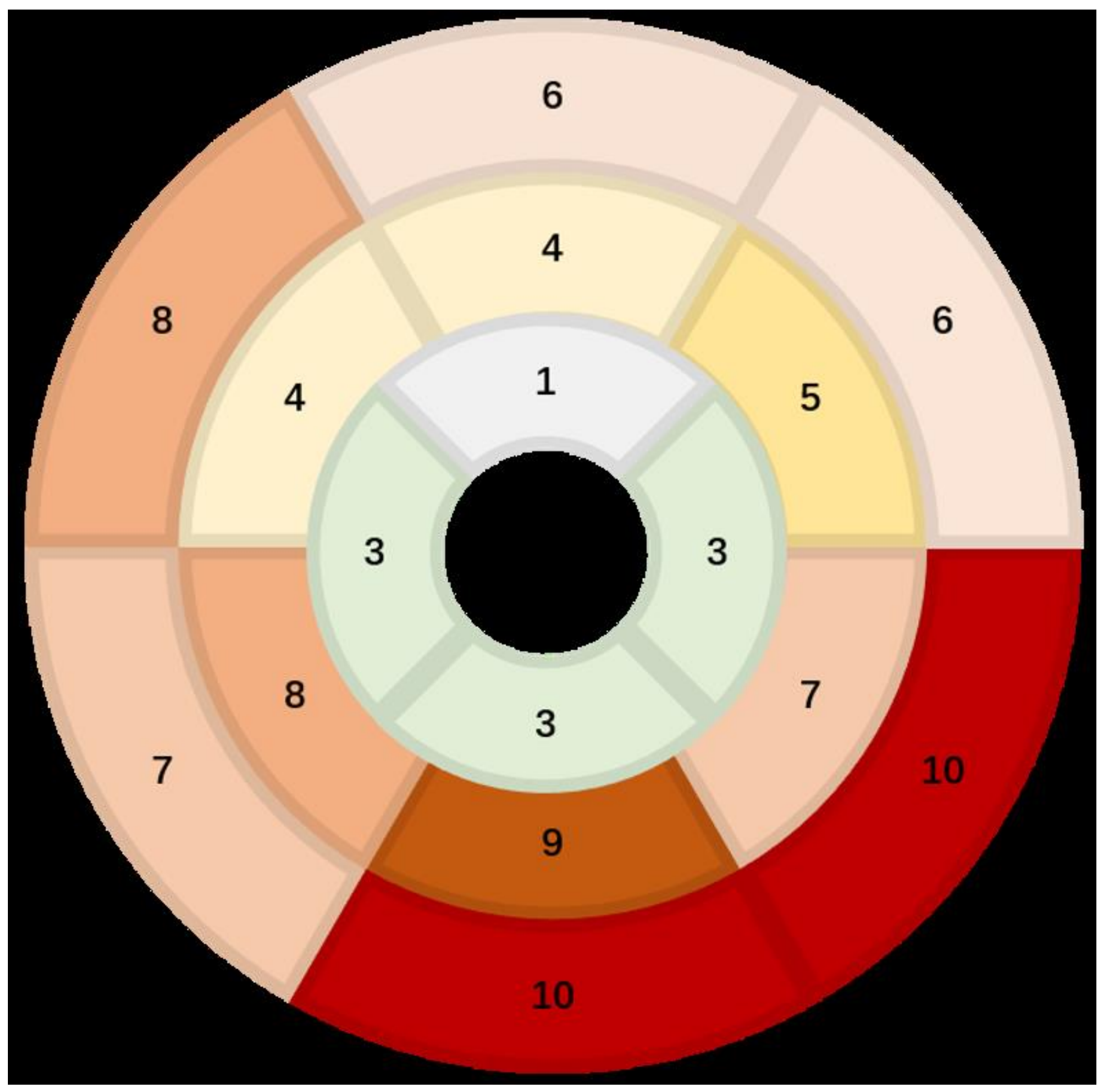

Figure 2

Dominant distribution of myocardial LGE segments in recovered COVID-19 patients. Number of myocardial LGE distributed in AHA 16 segments' model in all the 13 patients. 